\title{
Estudos iconográficos para a valorização do artesanato de Londrina e região
}

\author{
Iconographic Studies for Valuation of Craft of Londrina and Region \\ Moraes,Juliane Castilho; Graduanda; \\ Universidade Estadual de Londrina - UEL \\ julianecmoraes@gmail.com \\ Cavalcante, Ana Luisa Boavista Lustosa; Doutoranda; \\ Universidade Federal de Santa Catarina - UFSC \\ anaboavista@gmail.com
}

\begin{abstract}
RESUMO
Acompanhamentos realizados em comunidades de produção artesanal na região de Londrina, Paraná, por meio da técnica observação participante, se inserem nas atividades científicas da pesquisa já concluída: Indicadores de Design para o Desenvolvimento Sustentável (IDDS). A partir de tais acompanhamentos se observou a ínfima utilização em seus produtos de referências culturais da região. Este trabalho teve como objetivo levantar dados sobre a cultura imaterial e material da região de Londrina para futura aplicação em artesanato regional com ênfase em sua valorização. Para tanto, foi realizada a fundamentação teórica, abordando os temas, a saber: história; patrimônio cultural material e imaterial de Londrina; ícones regionais; design; identidade cultural; artesanato e sintaxe da linguagem visual. Depois se realizou a pesquisa dos ícones regionais e, ao final, a categorização dos ícones a partir de Barroso (1999), relacionando-os com os atrativos de Londrina, conforme Yamaki (2008), Lezo et al (2007) e Prefeitura Municipal de Londrina (2010).
\end{abstract}

Palavras-chave: cultura imaterial; artesanato; iconografia; valor agregado.

\begin{abstract}
Accompaniments made in communities of craft production in the region of Londrina, Paraná, through participant observation technique, falling within the scientific activities of research already completed: Design Indicators for Sustainable Development (IDDS). From such accompaniments observed use the tiny in their products of cultural references in the region. This study aimed to collect data about the material and immaterial culture of the region of Londrina for future application in regional crafts with an emphasis on recovery. Thereby, was carried out a theoretical foundation, addressing issues, namely: history, material and immaterial cultural heritage of Londrina; regional icons, design, cultural identity, crafts and visual language syntax. Then they conducted the survey of regional icons and in the end, the categorization of icons from Barroso (1999), relating them to the attractions of Londrina as Yamaki (2008), Lezo et al (2007) and Prefeitura Municipal de Londrina (2010).
\end{abstract}

Keywords: intangible culture, craft, iconography; value.

\section{Introdução}

A pesquisa, já concluída, "Indicadores de Design para o Desenvolvimento Sustentável (IDDS) - formação de rede interativa de reciclagem e reaproveitamento na produção artesanal de grupos de 
geração de trabalho e renda" a qual esse projeto se vincula, parte da premissa que toda região necessita de valorização cultural por meio de uma disseminação e compartilhamento do conhecimento sobre as potencialidades culturais locais. Tal valorização cultural permite que comunidades que dependem de produção local se desenvolvam com sustentabilidade nas dimensões social e cultural.

Londrina, importante cidade da região norte do Paraná, com 3.107 indústrias (PML/Secretaria do Planejamento - DP/GPI, 2002 apud MAFRA, 2002) e posição estratégica no eixo sul do Brasil e no bloco econômico do Mercosul, está inserida na região da Mata Atlântica com remanescentes florestais, tais como: a Mata dos Godoy; Parque Arthur Thomas; a RPPN Mata do Barão; e o parque ecológico Dr. Daisaku Ikeda, possui um ambiente urbano constituído por infraestrutura, economia, vida social e cultural e com especificidades de seu povo a partir de suas miscigenaç̧̃̃es e ocupações. Com potencial turístico a ser evidenciado, a cidade possui inúmeras potencialidades que ainda não foram exploradas e podem ser um recurso para expressar a cultura em produtos e serviços locais, com ênfase no artesanato.

O mapeamento da produção artesanal em Londrina, realizado pelo projeto de pesquisa IDDS, demonstrou que esta peculiaridade pode ser aplicada em produtos locais com ênfase no artesanato ou em pequenos produtores.

\section{Material e Métodos}

As estratégias de pesquisa adotadas foram a pesquisa bibliográfica e documental que procuraram explicar e discutir o tema com base em referências secundárias e primárias, respectivamente. $\mathrm{Na}$ primeira parte, conforme Martins e Theóphilo (2009, p.54), a pesquisa bibliográfica trata-se de um estratégia necessária para a condução de qualquer pesquisa científica e a mesma "procura explicar e discutir um assunto, tema ou problema com base em livros, periódicos [...]". A partir da definição do problema, realizou-se a busca e consulta de obras de referência. Na pesquisa documental, iniciou-se a documentação fotográfica de elementos visuais não publicados que foram aqui categorizados a partir de estudos de Barroso (1999).

Depois foram estudadas as Técnicas Visuais da Sintaxe da Linguagem Visual de Dondis (2000) para que os ícones pudessem ser futuramente utilizados pelos artesãos ou pequenos produtores locais.

\section{Londrina, sua identidade cultural e seus patrimônios materiais e imateriais}

Inicialmente, desbravada pelos ingleses nos anos de 1920, Londrina foi fundada em agosto de 1929 e elevada à condição de munícipio em 1934. Planejada em Londres e implantada pela Companhia de Terras Norte do Paraná para ser a capital da área de colonização, a "Pequena Londres" - como é conhecida - atraiu imigrantes: ingleses, italianos, japoneses, alemães, judeus, árabes; e migrantes: paulistas, mineiros, gaúchos e nordestinos. Foram o sólo fértil, conhecido como "terra roxa", formado por derramamento basáltico, e o café, os grandes atrativos de colonos e o que fez Londrina nos anos 1950 ser conhecida como a "Capital Mundial do Café" (ARCHELA et al, 2009).

O município é o segundo mais importante do Paraná em economia e em população com 506.645 habitantes (IBGE, 2010) e sede de sua região metropolitana, reconhecida, em 1998, e constituída por: Bela Vista do Paraíso, Cambé, Ibiporã, Londrina, Rolândia, Sertanópolis e Tamarana, onde estão 801.756 habitantes (IBGE, 2010). O setor de serviços e comércio é responsável por $75 \%$ do PIB londrinense. A cidade possui alto índice de inclusão social, quanto à educação, renda per capita e IDH (Índice de Desenvolvimento Humano) (ARCHELA et al, 2009).

Como em todo Brasil, com a miscigenação surgiu uma identidade polifacetada, cuja principal característica é a diversidade, sendo por isso difusa a idéia de arquétipos e referências tangíveis ou de características predominantes (BARROSO, 1999), Londrina também tem uma população resultante da mistura de povos. Essa mistura, no decorrer da história, resultou na influência de hábitos e costumes, expressos nas manifestações culturais e ambientais e impressos na paisagem (ARCHELA et al, 2009). Com o passar dos anos, os traços culturais trazidos pelos povos diversos que colonizaram o município, 
se misturaram e foram adaptados, resultando na identidade cultural dos londrinenses (LEZO et al, 2007).

Barroso (2012, p.1), afirma que

[...] reconhecer esta identidade está também em identificar e utilizar a força expressiva de muitos elementos de uso cotidiano, que de tão vistos ninguém mais os enxerga e de tão tocados ninguém mais os sente. São produtos e imagens banais que fazem parte indissociável de uma memória coletiva, que devem ser resgatados e incorporados ao acervo de símbolos que permita entender ou qualificar o conceito de pertinência cultural.

O Patrimônio Histórico-Cultural de um povo ou de um lugar é tudo aquilo que se relaciona com sua identidade, são todas as manifestações diferenciais de um grupo, sejam elas materiais ou imateriais. Elas representam simbolicamente as particularidades de um povo e podem estar intrinsecamente ligados ao seu dia-a-dia (LEZO et al, 2007).

Segundo o Instituto do Patrimônio Histórico e Artístico Nacional (IPHAN), os patrimônios culturais não são apenas imóveis oficiais isolados, atualmente sua concepção se estende a imóveis particulares, trechos urbanos, ambientes naturais paisagísticos, imagens, mobiliário, utensílios, dentre outros bens móveis.

O IPHAN considera dois tipos de patrimônio histórico-culturais e artísticos, o material e o imaterial. O Patrimônio Material é composto pelos bens tangíveis, ou seja, todos os bens palpáveis e concretos. As edificações, os sítios urbanos e paisagens, os elementos naturais, os vestígios arqueológicos, os documentos e as obras de arte, todos são considerados patrimônios materiais (LEZO et al, 2007). O Patrimônio Imaterial se compõe dos bens intangíveis, que não são palpáveis. São entendidos como patrimônios imateriais: as tradições, expressões orais, artísticas, sociais, rituais e atos festivos, conhecimentos e práticas relacionados à natureza e ao universo, técnicas artesanais tradicionais entre outras (LEZO et al, 2007).

O IPHAN afirma que

O Patrimônio Imaterial é transmitido de geração em geração e constantemente recriado pelas comunidades e grupos em função de seu ambiente, de sua interação com a natureza e de sua história, gerando um sentimento de identidade e continuidade, contribuindo assim para promover o respeito à diversidade cultural e à criatividade humana. (IPHAN, 2012, p.1).

Muitas vezes são tais patrimônios materiais e imateriais que caracterizam a identidade e as iconografias presentes em determinada região.

Iconografia é a identificação de imagens, histórias e alegorias e uma análise iconográfica pressupõe uma identificação exata dos motivos. É uma descrição e classificação de imagens (PANOFSKY, 1979, p. 51). Segundo SEBRAE/PR (2003), a iconografia pode ser entendida, como a coleção de signos e códigos pictóricos encontrados nas artes, arquitetura, artefatos, fauna, flora e paisagem, folclore e tradições populares. Em Londrina, por exemplo, a Prefeitura realizou um mapeamento dos pontos turístico do município. Esses pontos são alguns dos potencias iconográficos da cidade.

A partir da história de Londrina, sua identidade cultural e seus patrimônios materiais e imateriais pode-se identificar as principais potencialidades iconográficas da cidade.

Na tabela 1, relacionou-se os ícones com a categorização segundo Barroso (1999) que divide a cultura material em: Arte e Arquitetura (Sacra, popular / vernacular, pretérita e contemporânea); Artefatos (industriais ou artesanais: religiosos, utilitários, decorativos, lúdicos etc.); Folclore (música, danças, mitos, lendas, vestuário, culinária); Fauna e flora (representativa de animais, pássaros, flores, paisagens). Tais ícones foram pesquisados em diferentes fontes bibliográficas e alguns são citados em mais de uma fonte. Ao todo, contabilizam-se 68 ícones consultados em referências publicadas. 


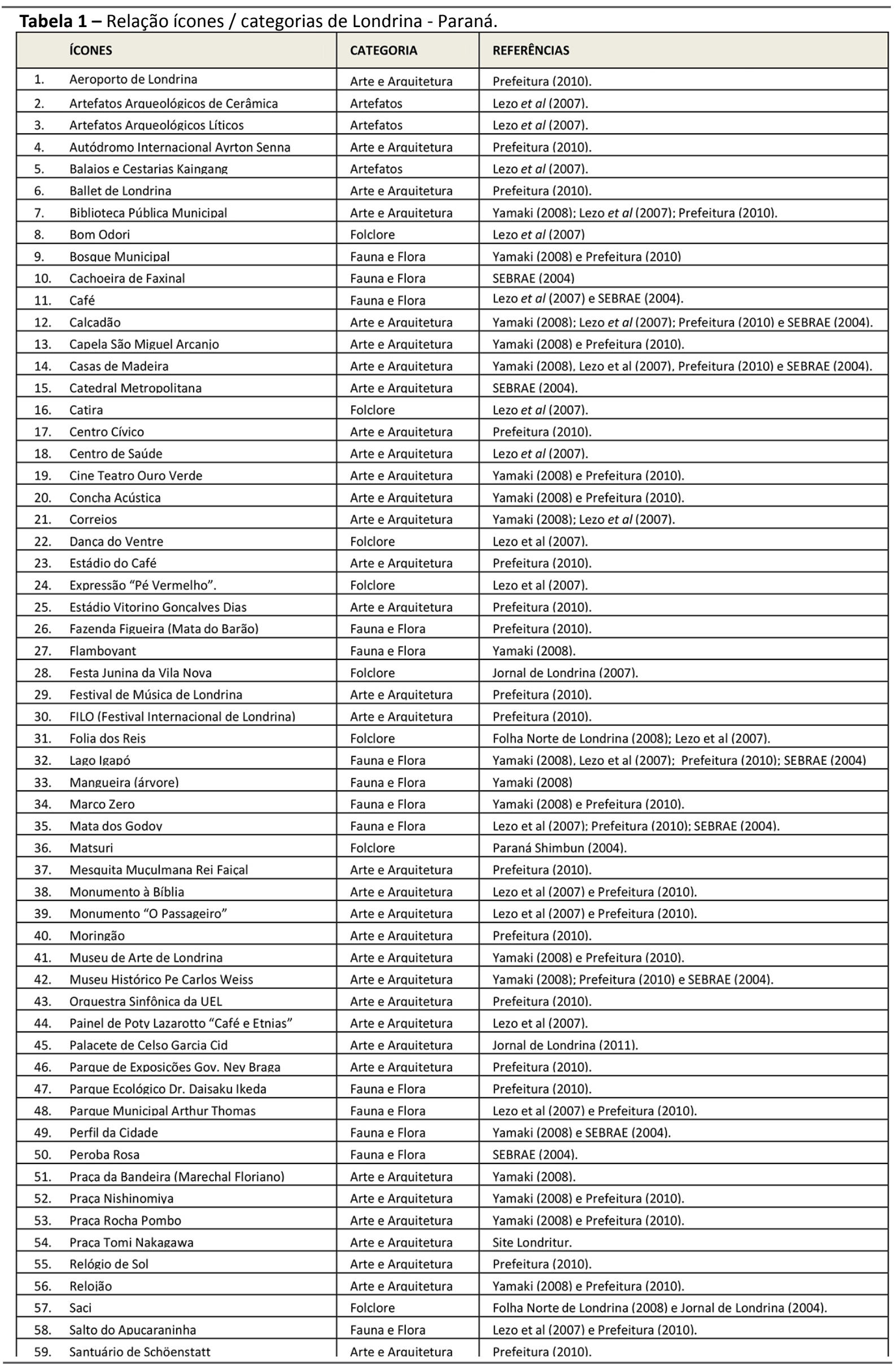


Estudos iconográficos para a valorização do artesanato de Londrina e região

\begin{tabular}{|rl|l|l|}
\hline 60. & Secretaria Municipal de Cultura & Arte e Arquitetura & Yamaki (2008); Lezo et al (2007) e Prefeitura (2010). \\
\hline 61. & Sotaque (com “R” carregado) & Folclore & Lezo et al (2007) \\
\hline 62. & Taiko & Folclore & Paraná Shimbun (2004). \\
\hline 63. & Teatro Zaqueu de Melo & Arte e Arquitetura & Yamaki (2008); Lezo et al (2007) e Prefeitura (2010). \\
\hline 64. & Templo Budista Honganii & Arte e Arquitetura & Prefeitura (2010). \\
\hline 65. & Terra Roxa & Fauna e Flora & SEBRAE (2004). \\
\hline 66. & Terminal Rodoviário de Londrina & Arte e Arquitetura & Prefeitura (2010). \\
\hline 67. & Universidade Estadual de Londrina & Arte e Arauitetura & Yamaki (2008), Prefeitura (2010) e SEBRAE (2004). \\
\hline 68. & Zerão & Fauna e Flora & Yamaki (2008); Lezo et al (2007) e Prefeitura (2010) \\
\hline
\end{tabular}

Fonte: própria (2011).

A representação das iconografias londrinenses é relevante, pois, segundo Barroso (1999), um dos componentes de uma sólida base de informações para um programa de artesanato deve estar relacionada ao resgate e valorização da cultura material e iconográfica da região onde as ações serão implantadas. Verificou-se que no Centro Público de Economia Solidária da cidade de 36 núcleos de produção apenas um utiliza os ícones da região.

Sobre essa questão Barroso menciona que

Desenvolver novos produtos artesanais de referência cultural significa valer-se de elementos que reportem o produto a seu lugar de origem, seja através do uso de certas matérias-primas ou técnicas de produção típicas da região, seja pelo uso de elementos simbólicos que façam explícita menção as origens de seus produtores ou de seus antepassados (BARROSO, 1999 apud MASCÊNE; TEDESCHI, 2012, p. 30).

Outro fator que evidencia a relevância dessa representação visual é a preferência do homem pela informação visual, conforme Dondis (2003), a experiência visual humana no aprendizado é fundamental para compreendermos o meio ambiente e reagir a ele. A maior força da linguagem visual é seu caráter imediato, através da qual nossa percepção do conteúdo e da forma é simultânea. Esta autora remete a "utilização de dados visuais para transmitir informações [que] representa a máxima aproximação que podemos obter com relação à verdadeira natureza da realidade." (DONDIS, 2003, p.7).

A linguagem visual, quando comparada à linguagem verbal e as mais de três mil línguas correntes no mundo, é mais universal, pois a visão é natural. Ao ver, vivenciamos diretamente os acontecimentos, descobrimos algo novo, conscientizamo-nos de nossos novos reconhecimentos e saberes, e percebemos as transformações se desenvolvendo. A visão passou a ter implicações mais abrangentes: ver agora remete a compreender. Expandimos nossa capacidade de entender e de criar mensagens visuais quando expandimos nossa capacidade de ver (DONDIS, 2003).

Segundo Yamaki (2008), o fato de Londrina ser uma cidade nova justifica a anulação das marcas do lugar. Pode ser que esta anulação leve a não preservação de importantes iconografias e patrimônios culturais da cidade como ocorreu com a retirada do Coreto e do monumento O Cristo Libertador, a demolição da casa da família de Roberto Julio Roehrig (a Casa dos Anões) e a revitalização do Calçadão, resultando na descaracterização do local.

Nas figuras 1 e 2, pode-se notar como era o Calçadão de Londrina em seu projeto original e como ele ficou após a revitalização, respectivamente. Percebe-se a perda de identidade, memória e de conceito, no qual era representado de forma geometrizada o Pinheiro do Paraná - uma das árvores nativas características da região - no desenho formado pelo petit-pavé . Aparecem também nas luminárias instaladas no local que lembram os pinheirais (ARCHELA et al, 2009). 


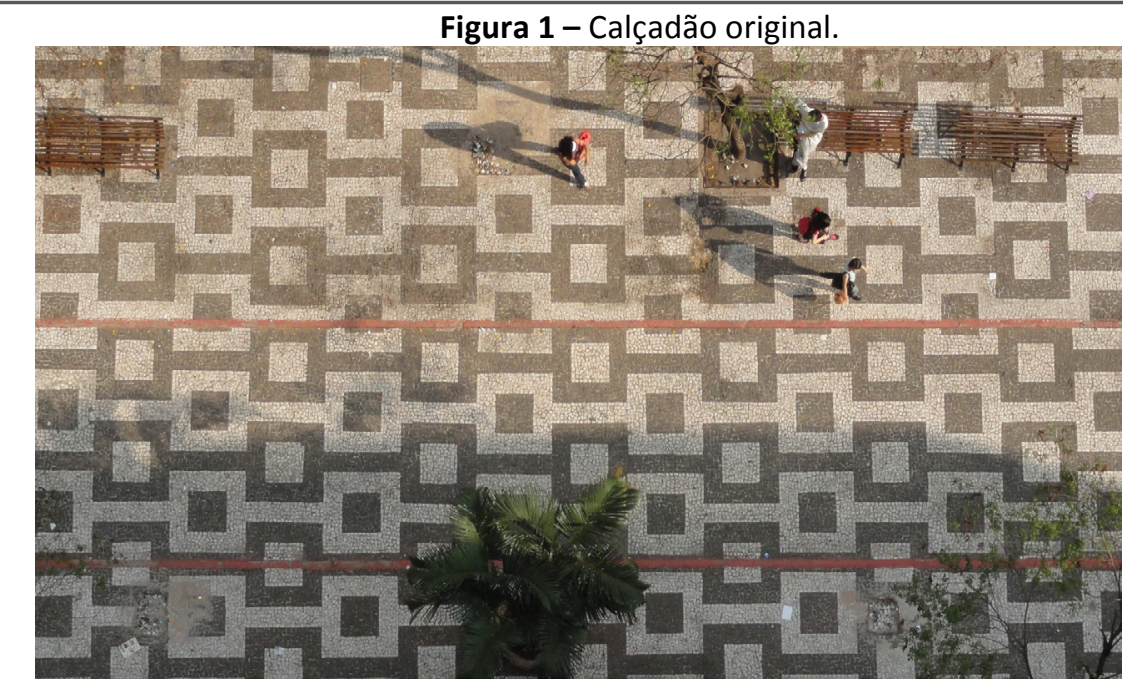

Fonte: própria, 2010.

Figura 2 - Calçadão reformado.

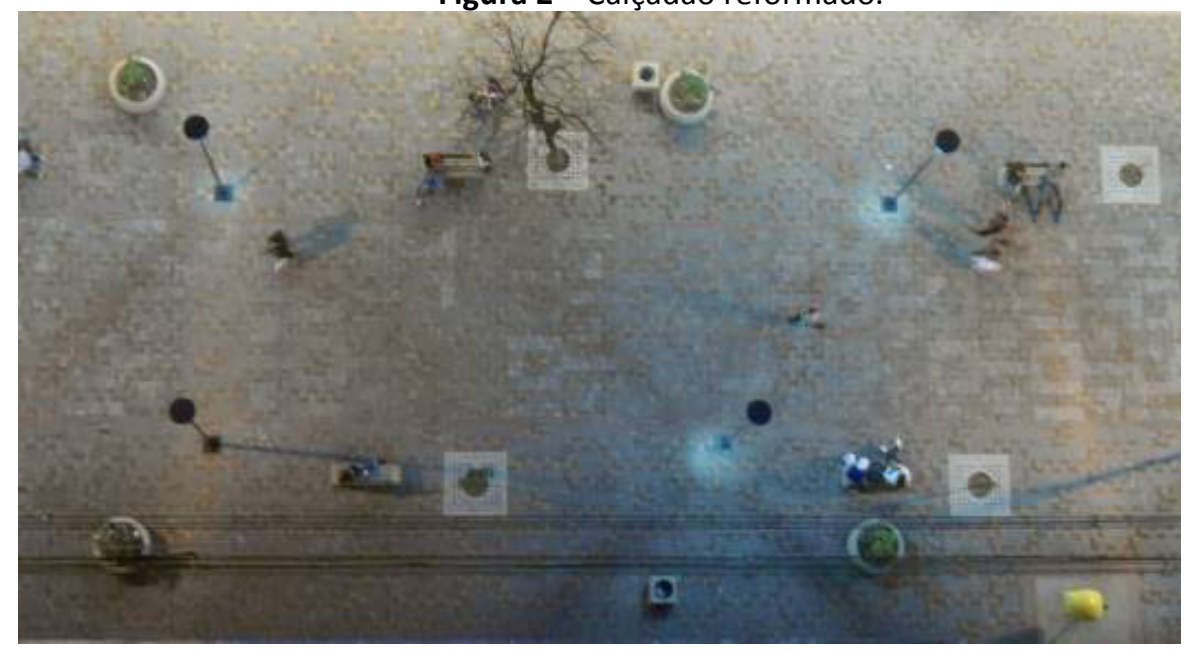

Fonte: própria, 2011.

Essa descaracterização se deve ao fato de que, com a nova pavimentação utilizada, a paver, as formas ficaram pouco evidenciadas devido à mudança das cores padrão e ao baixo contraste entre os elementos gráficos das mesmas - originalmente em preto e branco, perdendo a relação figura/fundo que de acordo com Lupton (2008, p.85) "definem a percepção visual". O Calçadão agora possui as cores preta, cinza, vermelha e amarela e suas luminárias deixaram de ter a forma estilizada do pinheiro do Paraná, obtendo uma configuração visual econômica, simples, minimizada, neutra e sem identidade visual.

Como já afirmava o arquiteto Le Corbusier "não sabemos para onde ir porque não sabemos de onde viemos." (LE CORBUSIER, 1928 apud YAMAKI, 2008). Portanto, é o conhecimento e o reconhecimento da identidade cultural, dos ícones e dos patrimônios histórico-culturais contidos no município que resultarão na preservação e na representação dos mesmos, por meio do artesanato e dos pequenos produtores. Essa representação reforçará o valor do artesanato e da identidade local (BARROSO, 1999).

A seguir, vemos alguns exemplos de artesanatos nacionais e internacionais que fizeram o uso das iconografias da região, agregando valor ao seu produto e reafirmando seu patrimônio históricocultural e sua identidade, estimulando, assim, o turismo local. Nos artesanatos nacionais, figura 3, é evidente o uso de elementos que os relacionem ao seu lugar de origem, por meio das matérias-primas e das técnicas de produção típicas da região. 


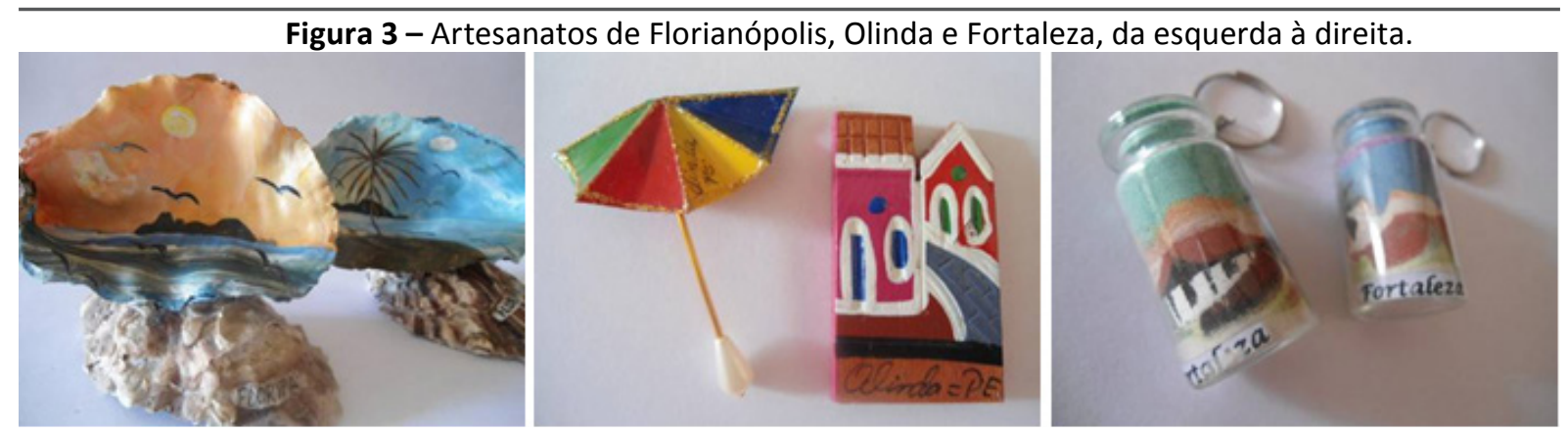

Fonte: própria, 2011.

Conforme na figura 3, percebemos que, nos artesanatos de Florianópolis, as pinturas nas conchas se reportam à praia Armação vista do Morro das Pedras. Nos de Olinda, os produtos artesanais se referem à construções histórias e ao frevo, dança folclórica da região. Por último, nos chaveiros de artesanato com areia colorida de Fortaleza que para a representação da paisagem local há o uso de uma técnica comum da região, a qual faz desenhos com areias coloridas dentro de pequenos recipientes de vidro.

Na figura 4, tem-se exemplos de artesanatos internacionais. Ambos holandeses, no primeiro, feito de porcelana, há pelo menos três ícones locais: os sapatos holandeses, os moinhos e as fitas nas cores da bandeira. O segundo produto, talhado em madeira, refere-se à tulipa, espécie de flor característica do país.

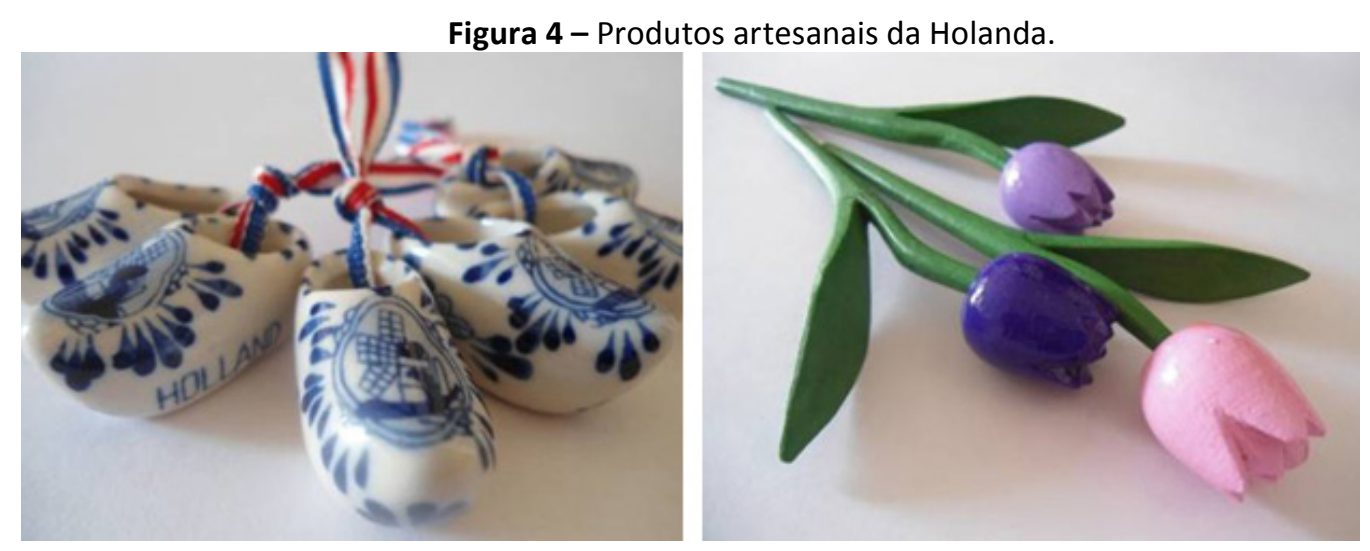

Fonte: própria, 2011.

As figuras anteriores mostram que as contribuições do emprego de iconografias locais no artesanato são inúmeras. Tais usos além de destacar a identidade e os atrativos regionais, incentiva o turismo e valoriza o trabalho artesanal. Esse fato confirma a importância de vincular os ícones de Londrina ao artesanato da cidade.

Conforme o mapeamento feito pelo projeto: Indicadores de design para o desenvolvimento sustentável, há cerca de 200 artesãos que trabalham em comunidades ou individualmente nas cidades de Londrina, Cambé, Ibiporã e Tamarana. Seus produtos são de artesanato indígena, tradicional, étnico, contemporâneo, diversas culturas urbanas e de trabalho manual sem transformação de matéria-prima e/ou sem originalidade. Estes últimos representam grande parte dos grupos visitados e que estão em busca de resposta mercadológica (CAVALCANTE; NASCIMENTO, 2009).

$\mathrm{O}$ artesanato da cidade deve ser incentivado e valorizado, pois, além de beneficiar esse grande número de artesãos da região, por ser um relevante gerador de trabalho e renda, sua produção é de baixo impacto ambiental e ao carregar traços de uma determinada cultura, conserva a identidade local. Apoiar este segmento do mercado significa contribuir para a solução de muitas mazelas sociais (CAVALCANTE, 2011).

Segundo o "Termo de Referência: atuação do Sistema SEBRAE no Artesanato", os filtros 
constituídos pelas categorias de artesanato são: Arte Popular; Artesanato Conceitual; Artesanato de Reciclagem; Artesanato de Referência Cultural; Artesanato Doméstico ou Trabalho Manual; Artesanato Indígena; Artesanato Tradicional; Industrianato (MASCÊNE; TEDESCHI, 2010).

A importância de aliar as categorias do artesanato às iconografias londrinenses para sua valorização está fundamentada em dois grandes movimentos paranaenses. 0 primeiro, conhecido como Paranismo, faz uso da diversidade cultural do estado - que tem origens indígenas, européias e ocidentais - para a elaboração de artesanatos com símbolos do Paraná. O incentivo da identidade cultural e sua valorização são as grandes preocupações desse movimento (CAVALCANTE et al, 2011).

O segundo é um projeto de pesquisa realizado pelo SEBRAE/PR, o qual resultou no livro "Iconografia do Paraná", teve como objetivo identificar os principais ícones presentes no estado. Esse projeto visou também evidenciar o potencial dos elementos pictóricos como um diferencial qualitativo que pode agregar valor à atividades econômicas ligadas à cultura, como artesanato, turismo, design, bens de consumo, dentre outras.

A publicação do SEBRAE/PR foi dividida em duas partes. A primeira parte possui uma apresentação de cada um dos atrativos paranaenses selecionados na pesquisa e sua síntese visual. A figura 5 é um exemplo disso e mostra a sintetização de dois ícones londrinense: o Calçadão e o Lago Igapó.

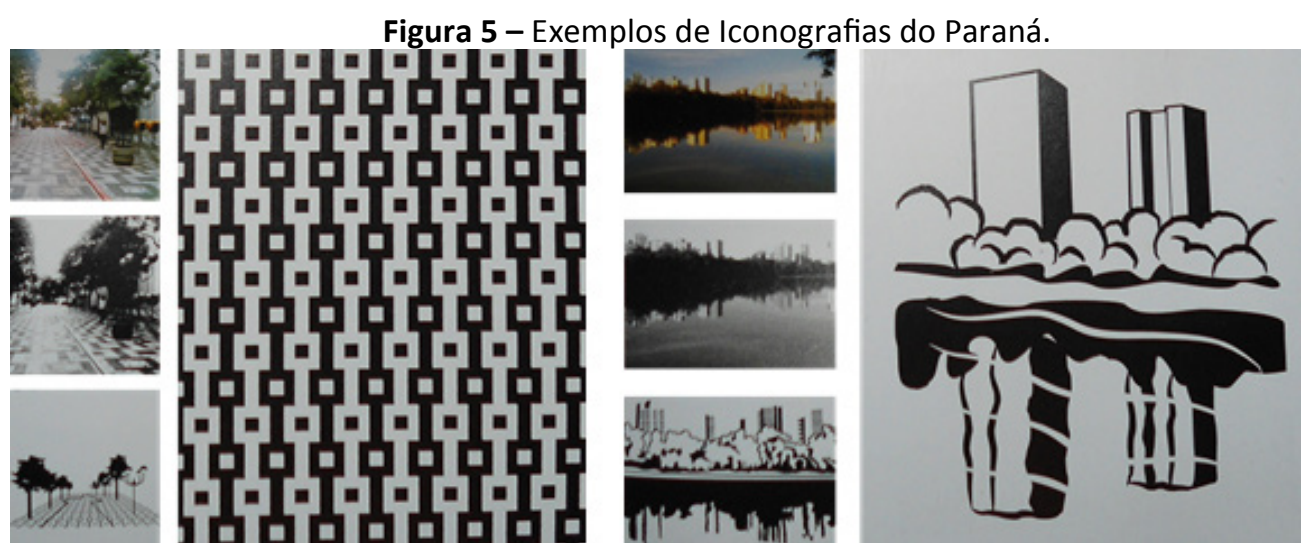

Fonte: SEBRAE. Serviço de Apoio às Micro e Pequenas Empresas do Paraná, 2004.

A segunda parte da publicação exemplifica as possibilidades de aplicações de alguns ícones em produtos artesanais e de pequenos produtores. A figura 6 mostra tais possibilidades para representar sintaticamente a Catedral de Maringá.

Figura 6 - Exemplos de Aplicações das Iconografias nos Artesanatos.

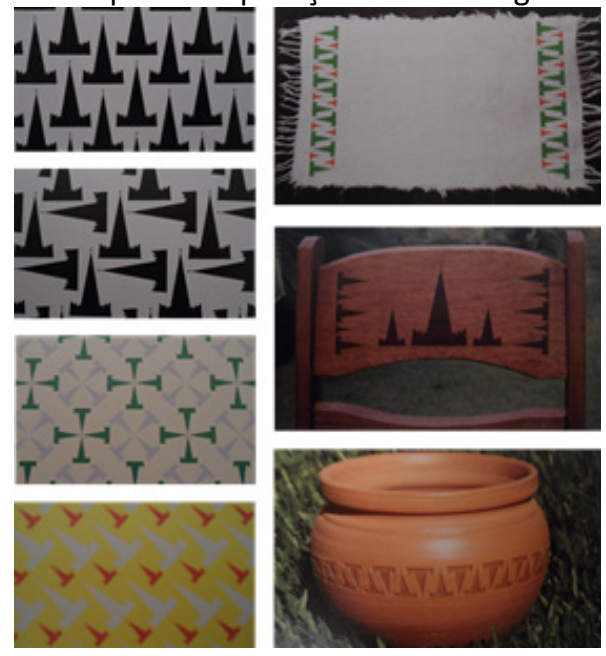

Fonte: SEBRAE. Serviço de Apoio às Micro e Pequenas Empresas do Paraná, 2004. 
Na figura 7, há alguns exemplos de aplicações em estampas, madeiras talhadas e cerâmicas moldadas, dentre vários outros usos possíveis do ícone paranaense: Araucária.

Figura 7 - Exemplos de Aplicações das Iconografias nos Artesanatos.
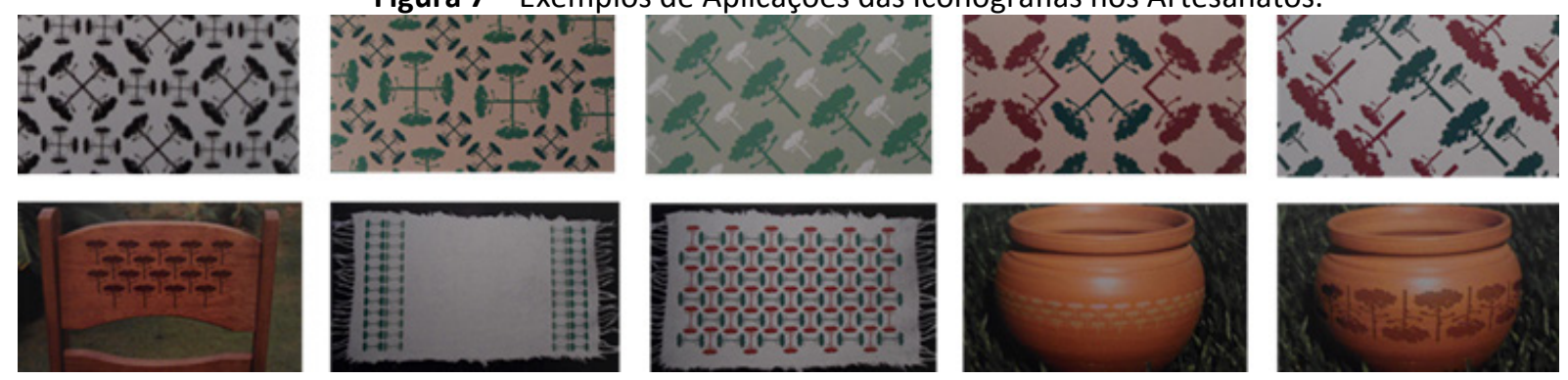

Fonte: SEBRAE. Serviço de Apoio às Micro e Pequenas Empresas do Paraná, 2004.

São aplicações sintetizadas com pregnância, como as das figuras 6 e 7, que se sugere para a aplicação dos potenciais ícones londrinenses nos produtos artesanais e de pequenos produtores. É importante que as aplicações artesanais sejam minimalistas e equilibradas, referindo-se, assim, às iconografias da cidade de forma simples, clara, rápida e pregnante.

Para a aplicação das iconografias de Londrina e região no artesanato local se realize com êxito, a aproximação entre o Design e o Artesanato é, também, muito importante. Visando, assim, explanações dos designers aos artesãos sobre as qualidades dos produtos; diferenciais entre produtos concorrentes no mercado; e instrução sobre durabilidade, originalidade, criatividade e acabamento das formas (simetria, fechamento, continuidade, equilíbrio, e outros conceitos da Gestalt; diversidade de formas, cores, texturas e outros elementos básicos da Sintaxe da Linguagem Visual). Isso, da mesma forma como foi feito pelo projeto: Indicadores de design para o desenvolvimento sustentável aos artesãos acompanhados.

\section{Conclusão}

Por ser uma atividade profissional que desenvolve produtos diante de necessidades humanas, constatamos que o Design tem uma grande responsabilidade em construir conhecimentos junto a esses micro-empreendimentos sociais, solidários e sustentáveis, contribuindo para a melhoria da qualidade de vida, preservação dos recursos naturais e preservação e valorização do patrimônio material e imaterial.

Portanto, conforme a pesquisa bibliográfica realizada e os resultados obtidos se confirmam como importantes o conhecimento e a aproximação da história, da identidade, dos patrimônios histórico-culturais e artísticos e, consequentemente, das iconografias da cidade. Tal conhecimento e sua posterior aplicação no artesanato da região, além de agregar valor aos produtos artesanais, valoriza e reafirma o trabalho artesanal, o patrimônio histórico-cultural e a identidade da cidade, estimulando, assim, o turismo local. Esse fato confirma ainda a importância de vincular os ícones de Londrina ao artesanato da cidade.

\section{Agradecimentos}

Ao Programa de Iniciação Científica (PROIC /UEL), à Pró-reitoria de Pesquisa e Pós-graduação (PROPPG /UEL) e ao Departamento de Design, ambos da Universidade Estadual de Londrina.

\section{Referências}

ALIGLERI, Micheli. Vila Nova mantém tradição de festa caipira. Jornal de Londrina. Londrina, 17 jun. de 2007. Cidade, p.9. 
ARCHELA, Rosely Sampaio; BARROS, Miriam Vizintim Fernandes (Org.). Atlas urbano de Londrina. Londrina: EDUEL, 2009.

BARROSO, Eduardo. Introdução e Metodologia. In: Identidade cultural: Iconografia do Paraná. Curitiba: SEBRAE/PR, 2004.

BARROSO, Eduardo. Design, identidade cultural e artesanato. Primeira Jornada Iberoamericana de Design no Artesanato Fortaleza, nov. 1999. Disponível em: <http://www.eduardobarroso.com.br/ artigos.htm>. Acesso em 04 jul. de 2011.

BARROSO, Eduardo. Reflexões De Eduardo Barroso Sobre Artesanato. In: NANDEVA - Programa Trinacional de Artesanato. Disponível em: <http://www.nandeva.org/pt-br/node/2776>. Acesso em 08 ago 2012.

CAVALCANTE, Ana Luisa Boavista Lustosa; FIALHO, Francisco Antônio Pereira; ROVER, Aires José. A produção artesanal no Paraná e o Governo Eletrônico. Revista Democracia Digital e Governo Eletrônico (ISSN 2175-9391), n 4, p. 68-79, 2011.

CAVALCANTE, Ana Luisa Boavista Lustosa; NASCIMENTO, Cristianne Cordeiro. Mapeamento de grupos de produção artesanal - um indicador de design para a sustentabilidade. Anais do $2^{\circ}$ Simpósio Brasileiro de Design Sustentável (II SBDS). São Paulo: Rede Brasil de Design Sustentável - RBDS, 2009.

DONDIS, Donnis. A. Sintaxe da linguagem visual. São Paulo: Martins Fontes, 2003.

IBGE. Resultados do Censo 2010. Disponível em: <http://www.censo2010.ibge.gov.br/-resultados_do_ censo2010.php>. Acesso em 04 jul. 2011.

LEMES, Francismar. O diabinho do pé-de-vento. Jornal de Londrina. Londrina, 29 mar. de 2004, p.7a.

LEZO, Denise; DORNELAS, Eline; ZANON, Elisa Roberta; MORAES, Vanda de. Reconhecendo o patrimônio cultural de Londrina. Londrina: Midiograf, 2007.

LONDRINATUR. Praça Tomie Nakagawa, <http://www.londrinatur.com.br/Londrina/-Turismo_ Londrina/Atrativos_Turisticos/Praca_Tomie_Nakagawa/2_27_1783.html>. Acesso em 04 jul. de 2011.

LUPTON, Ellen; PHILLIPS, Jennifer Cole. Novos fundamentos do design. São Paulo: Cosacnaify, 2008.

LUPORINI, Fábio. Tombado. Jornal de Londrina. Londrina, 29 mar. de 2004. Divirta-se, p.17.

MAFRA, Marcelo. O meio ambiente em Londrina - diferencial de qualidade para o desenvolvimento regional, CODEL - Companhia de Desenvolvimento de Londrina da Prefeitura Municipal de Londrina, 2005.

MARTINS, Gilberto de Andrade; THEÓPHILO, Carlos Renato. Metodologia da investigação científica para ciências sociais aplicadas. São Paulo: Atlas, 2009.

MASCÊNE, Durcelice; TEDESCHI, Mauricio. Termo de referência: atuação do Sistema SEBRAE no artesanato. Brasília: SEBRAE, 2010.

PANOFSKY, Erwin. Significado nas artes visuais. Tradução Maria Clara F. Kneese, J. Guinsburg. 2.ed. São Paulo: Perspectiva, 1979. (Debates 99).

Prefeitura Municipal de Londrina. Disponível em: <http://www1.londrina.pr.gov.br/>. Acesso em 04 jul. de 2011.

Prefeitura Municipal de Londrina. Pontos turísticos de Londrina. <http://maps.google.com.br/maps/ 
$\mathrm{ms} ? \mathrm{f}=\mathrm{q} \&$ source $=$ embed $\& \mathrm{hl}=\mathrm{pt}-\mathrm{BR} \&$ geocode $=\& \mathrm{~g}=$ Rodovia + Celso+Garcia + Cid,+ Km $.+379,+$ Londrina\&ie $=$ UTF8\&hq=Universidade+Estadual+de\&hnear=Londrina+-+PR\&msa=0\&msid=1111984392002554330 45.00047 ec4bf6cd3618ceb1\& $\|=-23.30064,-51.18187 \&$ spn=0.302709,0.439453\&z=11>. Acesso em 04 jul. de 2011.

SEBRAE. Serviço de Apoio às Micro e Pequenas Empresas do Paraná. Identidade cultural: Iconografia do Paraná. Curitiba: SEBRAE/PR, 2004.

THEODORO, Apolo. Lobisomem fora de época. Folha de Londrina, Londrina, 11 abr. de 2009. Folha Rural, p.2.

YAMAKI, Humberto. Guia do patrimônio cultural de Londrina. Londrina: Humanidades, 2008. 